\title{
IN-VITRO BEHAVIOR OF RESIN LUTING CEMENT MATERIAL POLYMERIZED WITH DIFFERENT LIGHT SOURCES UNDER DIFFERENT HYBRID CAD/CAM MATERIALS THICKNESSES
}

\author{
Ashraf Elsayed Nasr* and Ahmed Fawzy **
}

\begin{abstract}
The purpose of this in vitro study was to evaluate the effect of two types of modified CAD/ CAM restorative material and its thickness, together with the type of resin luting cement, and its method of curing on color difference $(\Delta E)$ and $\mathrm{VHN}$ as an indicator of the degree of polymerization of resin luting cement.

Materials and methods: A total of 36 groups were used in this study ( $n=5)$ where, 32 Groups representing the each of the two different resin luting cement materials, under each of the two different modified CAD/CAM materials interface with four different materials thicknesses $(0.5$ $\mathrm{mm}, 0.7 \mathrm{~mm}, 0.9 \mathrm{~mm}$ and $1.2 \mathrm{~mm}$ ) and polymerized with either conventional halogen or LED light curing system. Another four groups were prepared representing the control groups for each resin luting cement and light curing unit used. $\Delta E$ Measurement: Specimens in all groups was measured just after polymerization at the top of the specimens after removal of the ceramic face and Mylar strip to be compared with stored in dry boxes in darkened incubator at $37^{\circ} \mathrm{C}$ for one week to be subjected to the color measurement again at the surface of the specimens. Micro Hardness Measurement : The resin luting cement specimens were subjected to micro-hardness tester (Wilson ${ }^{\text {ò }}$ Hardness Tester, Model Tukon 1102, Buehler, Lake Bluff, IL, USA). The data obtained from the means of $\Delta \mathrm{E}$ and VHN test were subjected to analysis of variance (ANOVA) followed by Tukey's test at a $5 \%$ level of significance.
\end{abstract}

Results: Four-Way ANOVA was used to test the four main effects namely, type of indirect esthetic restorative material and its thickness, together with the type of resin luting cement, and its method of curing the types of resin luting cement, the mode of curing. The first main effect (type of modified CAD/CAM material) had two levels namely, Lava Ultimate, and Vita Enamic. The second main effect (modified CAD/CAM material thickness) had four levels namely, $0.5 \mathrm{~mm}, 0.7$ $\mathrm{mm}, 0.9 \mathrm{~mm}$ and $1.2 \mathrm{~mm}$. The third main effect (type of resin luting cement) had two levels namely Vario Link Dual and Nexus 3 LC. The fourth main effect (type of light curing unit) had two levels namely QTH and LED.

Conclusion: Within the limitation of this study, it could be concluded that, the thickness of the $\mathrm{CAD} / \mathrm{CAM}$ material and the type of the resin luting cement had a higher effect on the $\Delta \mathrm{E}$ and micro-hardness, hence the degree of maturation, of resin luting cement than did either the type of tested CAD/CAM materials or the curing units.

\footnotetext{
* Assistant Professor of Operative Dentistry, Cairo University

** Assistant Professor of Operative Dentistry, Suez Canal University
} 


\section{INTRODUCTION}

In the current century, esthetic dentistry has evolved to be one of the major backbones of every dental practice. Esthetic dentistry has a wide range starting from resin composite restoration and extending to the design and reconstruction of the patient smile, certainly all these procedure is considered practicing under the cosmetic umbrella.

In a trial to modify the properties of $\mathrm{CAD} /$ CAM ceramics different organic hybrid materials were introduced to the market. One of these hybrid CAD/CAM materials is Lava Ultimate (3M ESPE), a so-called "resin nano-ceramic". Lava Ultimate, named also "nanoparticle and nano-cluster-filled resin or "CAD/CAM (resin) composite", contains nano-ceramic particles (silica- and zirconia filler/ cluster filler) bound in a resin matrix.(1) The other resin-ceramic $\mathrm{CAD} / \mathrm{CAM}$ material is VITA ENAMIC (VITA Zahnfabrik), which also called "hybrid dental ceramic" containing a feldspathicbased ceramic network and a reinforcing polymer network. Previously also named "resin infused ceramic hybrid" or "polymer-infiltrated Feld spathic ceramic network material"(2). The polymer infiltrated ceramic network material was made in an attempt to mimic the mechanical behavior of enamel $^{(3)}$. In contrary to other ceramic CAD/CAM materials, ENAMIC is infiltrated with polymer instead of glass, and the most common monomers are Triethylene glycol dimethacrylate (TEGDMA) and Urethane dimethacrylate (UDMA). The ceramic network constitutes a three-dimensional framework of organized particles, in comparison to the scattered distribution of filler particles in traditional resin composites. ${ }^{(4)}$

Disregarding the varying nomenclature due to the different composition of the two materials, both manufactures claim their material to have numerous advantages ${ }^{(5-7)}$. As a result of the resin component, lower brittleness compared to pure ceramic and modified abrasion behavior than composite. On the other hand, compared to silicate ceramic, the feasibility for milling of restorations with thinner walls increased, favoring minimally invasive restorations.

Resin luting cements, have gained a wide range of usage with inlay / onlay, posts and fixed prosthodontics, as they were proven to boost mechanical, physical, and adhesive, even esthetical properties of restorative systems ${ }^{(8)}$. Further, they provide adequate stability and increased fracture resistance of overlying ceramic restorations, together with an optimal esthetic result. Presently, resin luting cements grew the ability to modify the final shade match of the final indirect restoration as a result of the accessibility of their different shades, permitting clinicians obtain desirable esthetics.

It is well known that the success of an indirect esthetic restoration is primly dependent on the bond durability of both ceramic/luting cement and luting cement/tooth. Yet esthetic considerations are not to be neglected, as the final color of an indirect esthetic restoration is not only affected by the thickness, optical and surface properties of restorative material used, but also by the color, translucency, and thickness of the underlying resin luting cement which plays a crucial role in determining the final color of restorations ${ }^{(9-11)}$.

Nowadays, different manufacturers have supplied the market with a wide range of shades for resin luting cements in an attempt to enhance final color match for indirect esthetic restorations in order to achieve their required esthetic goals. However, the impact of cement shades on the final color of ceramic restorations remains controversial.

The purpose of this in vitro study was to evaluate the effect of type of indirect esthetic restorative material and its thickness, together with the type of resin luting cement, and its method of curing on color difference $(\Delta E)$ and degree of polymerization of resin luting cement. 
The total color difference is described by $\Delta E=\left[\left(\Delta L^{*}\right)^{2}+\left(\Delta a^{*}\right)^{2}+\left(\Delta b^{*}\right)^{2}\right]^{1 / 2(12)}$. Several studies have shown that color differences greater than one unit $(\Delta E>1)$ can be noticed by half the number of observers, while general population can differentiate color differences of value $\Delta E>3.3$, which can be considered clinically significant ${ }^{(13-15)}$.

The purpose of this study was to evaluate the $\Delta E$ and $V H N$ as an indicator to the degree of conversion of the resin luting cements, polymerized two different methods under different thicknesses of two different CAD/CAM materials.

\section{METHODS AND MATERIALS}

A total of 36 groups were used in this study $(n=5)$ where, 32 Groups representing the each of the two different resin luting cement materials, under each of the two different modified CAD/CAM materials interface with four different materials thicknesses $(0.5 \mathrm{~mm}, 0.7 \mathrm{~mm}, 0.9 \mathrm{~mm}$ and $1.2 \mathrm{~mm})$ and polymerized with either conventional halogen or LED light curing system. Variables tested in the study and their interaction is illustrated in table
(4\&5). An extra Tested four groups for each tested cement using both curing system manufactured without any interfacing ceramic materials and cured either by QTH or LED, used as control group. List of CAD/CAM materials [table (1)], list of curing lights specifications is given in table (2), and list of resin luting cement materials' specifications used in this study is demonstrated in table (3).

The split Teflon rings were assembled over glass slide in order to make resin cement sample of $2 \mathrm{~mm}$ thickness and $7 \mathrm{~mm}$ diameter. Dual-cured and light-cured resin cement was firmly pressed under a standardized $5 \mathrm{~kg}$ of load $3 \mathrm{~min}$ in the Teflon mold covered with Mylar strip (Alsip; GC America INC.) Individually on the upper side to ensure even and smooth surface. Sample without any interface ceramic material use as control group.

Another groups of both resin cements were fabricated using the same technique but with both ceramic materials with different thickness on the top as interface. All samples were polymerized using the conventional halogen and LED light curing system for $40 \mathrm{sec}$.

TABLE (1) List of CAD/CAM materials used in the study

\begin{tabular}{|c|c|c|c|c|c|c|c|}
\hline \multirow{3}{*}{ Material } & \multirow{3}{*}{ Type } & \multirow{3}{*}{$\frac{\mathbb{\pi}}{\tilde{\pi}}$} & \multirow{3}{*}{ Manufacturer } & \multirow{3}{*}{$\begin{array}{l}\text { 导 } \\
\text { صं }\end{array}$} & \multicolumn{3}{|c|}{ Composition } \\
\hline & & & & & \multirow{2}{*}{ Monomer } & \multicolumn{2}{|l|}{ Filler } \\
\hline & & & & & & Composition & Mass\% \\
\hline $\begin{array}{l}\text { Lava }^{\mathrm{TM}} \\
\text { Ultimate }\end{array}$ & $\begin{array}{l}\text { Composite } \\
\text { Resin }\end{array}$ & A1 & $\begin{array}{c}\text { 3M ESPE St.Paul } \\
\text { MN, USA }\end{array}$ & $\frac{\hat{m}}{\stackrel{+}{g}}$ & $\begin{array}{l}\text { Bis-GMA, } \\
\text { UDMA, Bis-EMA, } \\
\text { TEGDMA }\end{array}$ & $\begin{array}{c}\mathrm{SiO} 2(20 \mathrm{~nm}) \mathrm{ZrO}_{2}(4-11 \mathrm{~nm}), \\
\text { Aggregated } \mathrm{ZrO}_{2} / \mathrm{SiO}_{2} \text { Cluster } \\
\left(\mathrm{SiO}_{2}=20 \mathrm{~nm}, \mathrm{ZrO}_{2}=4-11 \mathrm{~nm}\right.\end{array}$ & 80 \\
\hline $\begin{array}{c}\text { Vita } \\
\text { Enamic } ®\end{array}$ & $\begin{array}{l}\text { Hybrid } \\
\text { ceramic }\end{array}$ & A1 & $\begin{array}{c}\text { Vita ZahnfabrikH. } \\
\text { Rauter, Bad } \\
\text { Säckingen, } \\
\text { Germany }\end{array}$ & 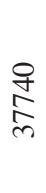 & UDMA, TEGDMA & $\begin{array}{c}\text { Feldspar ceramic enriched with } \\
\text { aluminum oxide }\end{array}$ & 86 \\
\hline
\end{tabular}

Bis-GMA:bisphenol A diglycidylether methacrylate; Bis-MEPP: 2,2-Bis (4-methacryloxypolyethoxyphenyl) propane; UDMA:urethanedimethacrylate; TEGDMA :triethylene glycol dimethacrylate; Bis-EMA: ethoxylatedbisphenol-A dimethacrylate; DMA: dimethacrylate. 
TABLE (2): List of different types of light curing system used in the study.

\begin{tabular}{|c|c|c|c|c|}
\hline Type & Unit & Intensity $\mathrm{mW} / \mathrm{cm}^{2}$ & Time (s) & Total Energy $\mathrm{mW} / \mathrm{cm}^{2}$ \\
\hline QTH & $\begin{array}{c}\text { Hilux curing light, BenliogbrFnc, Ankara, } \\
\text { Turkey Batch number 3051144 }\end{array}$ & 450 & 40 & 9000 \\
\hline Monowave LED & $\begin{array}{c}\text { Elipar S10,3M ESPE, Seefeld, Germany, Batch } \\
\text { number D-82229 }\end{array}$ & 1200 & 40 & 18.000 \\
\hline
\end{tabular}

TABLE (3): List of resin luting cement materials' specifications used in this study.

\begin{tabular}{|c|c|c|c|c|}
\hline Material & Manufacture & Monomer & Lot Number & Shade \\
\hline $\begin{array}{c}\text { Vario link Dual light } \\
\text { and self-curing }\end{array}$ & $\begin{array}{c}\text { Ivoclarvivadent AG, } \\
\text { SchaanLechtenstein }\end{array}$ & $\begin{array}{c}\text { Bis-GMA UDMA TEGDMA } \\
\text { Filler Initiator Stabilize }\end{array}$ & P39409 & R6551 \\
\hline Nexus 3 Light cured & Kerr, orange, CS,USA & Bis-GMA DMA & 4691126 & white \\
\hline
\end{tabular}

TABLE (4) Variables tested in the study.

\begin{tabular}{|c|c|c|}
\hline Variable & Symbol & Refers to \\
\hline \multirow{2}{*}{ Resin Luting Cement } & $\mathrm{R} 1$ & Variolinkdaul \\
\cline { 2 - 3 } & $\mathrm{R} 2$ & Nexus 3 light \\
\hline \multirow{2}{*}{ CAD/CAM Materials } & $\mathrm{C} 1$ & Lava ultimate. \\
\cline { 2 - 3 } & $\mathrm{C} 2$ & Vita Enamic. \\
\hline \multirow{2}{*}{ Light Curing Unit } & $\mathrm{L} 1$ & LED \\
\cline { 2 - 3 } & $\mathrm{L} 2$ & $0.5 \mathrm{~mm}$ \\
\hline \multirow{3}{*}{ CAD/CAM Materials Thicknesses } & $\mathrm{T} 1$ & $0.7 \mathrm{~mm}$ \\
\cline { 2 - 3 } & $\mathrm{T} 2$ & $0.9 \mathrm{~mm}$ \\
\cline { 2 - 3 } & $\mathrm{T} 3$ & $1.2 \mathrm{~mm}$ \\
\hline
\end{tabular}

TABLE (5) Interaction between different tested variable

\begin{tabular}{|c|c|c|c|c|c|c|c|c|c|c|c|c|c|c|c|c|c|c|c|c|c|c|c|c|c|c|c|c|c|c|c|c|c|c|c|}
\hline \multicolumn{18}{|c|}{ R1 } & \multicolumn{18}{|c|}{ R2 } \\
\hline \multirow{2}{*}{\multicolumn{2}{|c|}{\begin{tabular}{c|c}
\multicolumn{2}{c}{$\mathbf{C}_{0}$} \\
$L_{1}$ & $L_{2}$
\end{tabular}}} & \multicolumn{8}{|c|}{$\mathrm{C}_{1}$} & \multicolumn{8}{|c|}{$\mathrm{C}_{2}$} & c & & \multicolumn{8}{|c|}{$\mathrm{C}_{1}$} & \multicolumn{8}{|c|}{$\mathrm{C}_{2}$} \\
\hline & & $\mathrm{TI}$ & T2 & T3 & $T 4$ & \multicolumn{3}{|c|}{$\mathbf{L}_{2}$} & $T 4$ & \multicolumn{4}{|c|}{$\mathbf{L}_{1}$} & \multicolumn{4}{|c|}{$L_{2}$} & \multicolumn{2}{|c|}{\begin{tabular}{l|l}
$\mathbf{L}_{1}$ & $\mathbf{L}_{2}$ \\
&
\end{tabular}} & \multicolumn{4}{|c|}{$\mathbf{L}_{1}$} & \multicolumn{2}{|r|}{$\frac{\mathrm{L}}{\mathrm{T} 2}$} & \multicolumn{2}{|c|}{\begin{tabular}{|l|l}
\multicolumn{1}{|l|}{} & \\
T3 & T4 \\
\end{tabular}} & \multicolumn{2}{|r|}{$\frac{\mathrm{L}}{\mathrm{T} 2}$} & \multicolumn{2}{|c|}{\begin{tabular}{|l|l} 
T3 & \\
\end{tabular}} & & \multicolumn{2}{|c|}{\begin{tabular}{|l|l|}
$\mathrm{L}_{2}$ & \\
T3 & T4 \\
\end{tabular}} \\
\hline $\mathrm{R}$ & $R$ & $\mathrm{R}$ & $R$ & $\mathrm{R}$ & $\mathrm{R}$ & $\mathrm{R}$ & $R$ & $\mathrm{R}$ & $\mathrm{R}$ & $\mathrm{R}$ & $\mathrm{R}$ & $\mathrm{R}$ & $\mathrm{R}$ & $\mathrm{R}$ & $\mathrm{R}$ & $R$ & $R$ & $R$ & $R$ & $R$ & $R$ & $R$ & $R$ & $R$ & $R$ & $R$ & $R$ & $R$ & $R$ & $R$ & $\mathrm{R}$ & $\mathrm{R}$ & $R$ & $P$ & $R$ \\
\hline 1 & 1 & 1 & 1 & 1 & 1 & 1 & 1 & 1 & 1 & 1 & 1 & 1 & 1 & 1 & 1 & 1 & 1 & 1 & 1 & 2 & 2 & 2 & 2 & 2 & 2 & 2 & 2 & 2 & 2 & 2 & 2 & 2 & 2 & 0 & \\
\hline & & & & & & & & & & & & & & & & & & & & & & & & & & & & & & & & & & & \\
\hline C & $\mathrm{C}$ & $\mathrm{C}$ & $\mathrm{C}$ & $\mathrm{C}$ & C & C & C & C & C & C & $\mathrm{C}$ & $\mathrm{C}$ & C & C & $\mathrm{C}$ & $\mathrm{C}$ & $\mathrm{C}$ & $\mathrm{C}$ & C & $\mathrm{C}$ & $\mathrm{C}$ & $\mathrm{C}$ & $\mathrm{C}$ & C & $\mathrm{C}$ & $\mathrm{C}$ & $\mathrm{C}$ & C & C & $\mathrm{C}$ & C & C & $\mathrm{C}$ & $\mathrm{C}$ & c \\
\hline 0 & 0 & 1 & 1 & 1 & 1 & 1 & 1 & 1 & 1 & 2 & 2 & 2 & 2 & 2 & 2 & 2 & 2 & 0 & 0 & 1 & 1 & 1 & 1 & 1 & 1 & 1 & 1 & 2 & 2 & 2 & 2 & 2 & 2 & 2 & 2 \\
\hline $\mathrm{L}$ & $\mathrm{L}$ & $\mathrm{L}$ & $\mathrm{L}$ & $\mathrm{L}$ & $\mathrm{L}$ & $\mathrm{L}$ & $\mathrm{L}$ & $\mathrm{L}$ & $\mathrm{L}$ & $\mathrm{L}$ & $\mathrm{L}$ & $\mathrm{L}$ & $\mathrm{L}$ & $\mathrm{L}$ & $\mathrm{L}$ & $\mathrm{L}$ & $\mathrm{L}$ & $\mathrm{L}$ & $\mathrm{L}$ & $\mathrm{L}$ & $\mathrm{L}$ & $\mathrm{L}$ & $\mathrm{L}$ & $\mathrm{L}$ & $\mathrm{L}$ & $\mathrm{L}$ & $\mathrm{L}$ & $\mathrm{L}$ & $\mathrm{L}$ & $\mathrm{L}$ & $\mathrm{L}$ & $\mathrm{L}$ & $\mathrm{L}$ & $\mathrm{L}$ & L \\
\hline 1 & 2 & 1 & 1 & 1 & 1 & 2 & 2 & 2 & 2 & 1 & 1 & 1 & 1 & 2 & 2 & 2 & 2 & 1 & 2 & 1 & 1 & 1 & 1 & 2 & 2 & 2 & 2 & 1 & 1 & 1 & 1 & 2 & 2 & 2 & 2 \\
\hline $\mathrm{T}$ & $\mathrm{T}$ & $\mathrm{T}$ & $\mathrm{T}$ & $\mathrm{T}$ & $\mathrm{T}$ & $\mathrm{T}$ & $\mathrm{T}$ & $\mathrm{T}$ & $\mathrm{T}$ & $\mathrm{T}$ & $\mathrm{T}$ & $\mathrm{T}$ & $\mathrm{T}$ & $\mathrm{T}$ & $\mathrm{T}$ & $\mathrm{T}$ & $\mathrm{T}$ & $\mathrm{T}$ & $\mathrm{T}$ & $\mathrm{T}$ & $\mathrm{T}$ & $\mathrm{T}$ & $\mathrm{T}$ & $\mathrm{T}$ & $\mathrm{T}$ & $\mathrm{T}$ & $\mathrm{T}$ & $\mathrm{T}$ & $\mathrm{T}$ & $\mathrm{T}$ & $\mathrm{T}$ & $\mathrm{T}$ & $\mathrm{T}$ & $\mathrm{T}$ & $\mathrm{T}$ \\
\hline 0 & 0 & 1 & 2 & 3 & 4 & 1 & 2 & 3 & 0 & 1 & 2 & 3 & 4 & 1 & 2 & 3 & 4 & 0 & 0 & 1 & 2 & 3 & 0 & 1 & 2 & 3 & 4 & 1 & 2 & 3 & 4 & 1 & 2 & 3 & 4 \\
\hline
\end{tabular}


For all the specimens light curing was applied only to the top surface of the samples according to each group testing condition. The surface of the light guide was applied directly in contact to the Mylar strip covering the top surface of the sample or the surface of interfacial ceramics according to testing group. Both type of cement light cured and dual cure were subjected to light using for $40 \mathrm{sec}$. with both light curing units. The output of the curing units was checked with radiometer (curing Radiometer Model 100, Kerr crop. Orange, CA, USA).

No polishing was used in order to avoid any modification of the surface which may influence on the results.

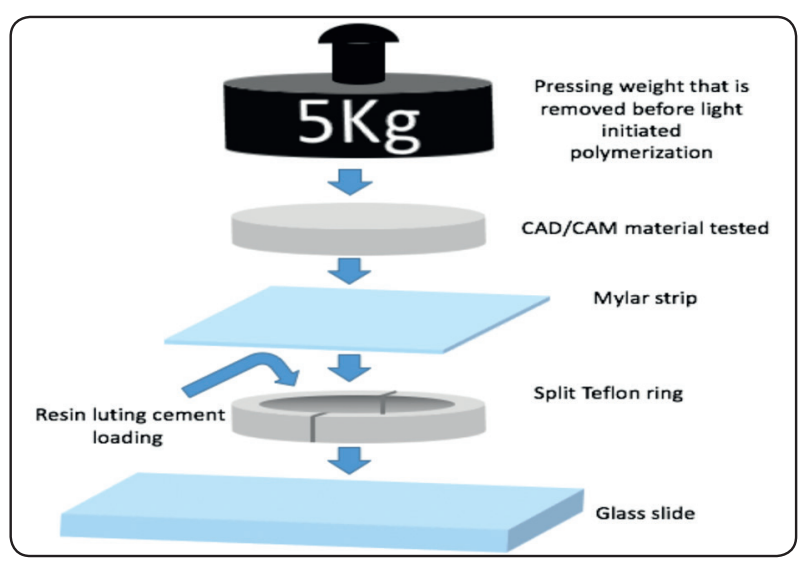

Fig. (1) The split Teflon rings were assembled over glass slide covered with Mylar strip with CAD/CAM material and the applied load.

\section{Color Difference $(\Delta \mathrm{E})$ measurement}

The color of all specimens in all groups was measured just after polymerization at the top of the specimens after removal of the ceramic face and Mylar strip to be compared with stored in dry boxes in darkened incubator at $37^{\circ} \mathrm{C}$ for one week to be subjected to the color measurement again at the surface of the specimens. The color measurement was performed according to the CIE $L^{*} a^{*} b^{*}$ system and mean $L^{*}, a^{*}, b^{*}$ values for each material was calculated. The total color change (obtained was calculated for each specimen using the equation). All measurements were made on white colored back-ground for standardization of the measurement.

$$
\Delta \mathrm{E}=\sqrt{\left(\mathrm{L}_{2}^{*}-\mathrm{L}_{1}^{*}\right)^{2}+\left(\mathrm{a}_{2}^{*}-\mathrm{a}_{1}^{*}\right)^{2}+\left(\mathrm{b}_{2}^{*}-\mathrm{a}_{1}^{*}\right)^{2}}
$$

The color and color difference of each specimen were measured by spectrophotometer (Aretag Macbeth ). The color of each sample was detected from spectral reflectance measurement which were carried out using spectrophotometer. Where $\mathrm{L}^{*}$ is the lightness, $a^{*}$ is green-red $\left(-a^{*}=\right.$ green; $+a^{*}=$ red $)$ and $b^{*}$ is blue-yellow $\left(-b^{*}=\right.$ blue; $+b^{*}=$ yellow $)$.

\section{Micro Hardness Measurement}

The resin cement specimens were subjected to micro-hardness tester (Wilson ${ }^{\circ}$ Hardness Tester, Model Tukon 1102, Buehler, Lake Bluff, IL, USA) and Vickers hardness numbers were determined. The test was carried out by using a load of $50 \mathrm{gm}$ for 15 seconds dwell time. The Vickers's hardness number $\left(\mathrm{N} / \mathrm{mm}^{2}\right)$ was recorded as an average of three readings for each surface of each specimen

\section{Statistical analysis}

The data obtained from the means of $\Delta \mathrm{E}$ and VHN test were subjected to analysis of variance (ANOVA) followed by Tukey's test at a 5\% level of significance.

\section{RESULTS}

In the current study Four-Way ANOVA was used to test the four main effects namely, type of indirect esthetic restorative material and its thickness, together with the type of resin luting cement, and its method of curing the types of resin luting cement, the mode of curing. The first main effect (type of modified CAD/CAM material) had two levels namely, Lava Ultimate, and Vita Enamic. The second main effect (modified CAD/CAM material thickness) had four levels namely, $0.5 \mathrm{~mm}, 0.7 \mathrm{~mm}$, $0.9 \mathrm{~mm}$ and $1.2 \mathrm{~mm}$. The third main effect (type of resin luting cement) had two levels namely Vario 
Link Dual and Nexus 3 LC. The fourth main effect (type of light curing unit) had two levels namely QTH and LED.

\section{Color Difference $(\Delta E)$}

The mean $\Delta \mathrm{E}$ values and standard deviations of tested groups are presented in Table (6) and Fig (2). No significant interaction was detected between the four main effects. It was clear that any increase in thickness of either of the CAD/CAM materials used in the current study led to an increase in $\Delta \mathrm{E}$ values, and this increase was significant mostly in large thicknesses. Post Hoc test of the tested groups revealed that through out the study, Lava Ultimate
$\mathrm{C} 1$ groups gave higher mean $\Delta \mathrm{E}$ values than did Vita Enamic C2 groups. And it was noticed that Nexus 3 LC R2 groups gave significantly lower mean $\Delta$ E values than Vario Link daul R1 corresponding groups.

Post Hoc test of the tested groups also showed that for Vario Link dual R1, upon increasing the Lava Ultimate $\mathrm{C} 1$ material thicknesses to $0.9 \mathrm{~mm}$ T3 or more, for either QTH or LED, statistical significant difference starts to appear in the mean $\Delta \mathrm{E}$ values compared to the control group. The same was detected for the Vita Enamic C2 groups cured with QTH L1 but not with the groups cured

TABLE (6) Mean $\Delta \mathrm{E}$ of tested groups.

\begin{tabular}{|c|c|c|c|c|c|}
\hline \multirow{2}{*}{\multicolumn{2}{|c|}{ Control }} & \multicolumn{2}{|c|}{ Vario Link daul R1 } & \multicolumn{2}{|c|}{ Nexus 3 LC R2 } \\
\hline & & \multirow{2}{*}{$\begin{array}{c}\text { QTH L1 } \\
2.14^{\mathrm{d}} \\
\end{array}$} & \multirow{2}{*}{$\begin{array}{c}\text { LED L2 } \\
1.87^{\mathrm{de}} \\
\end{array}$} & \multirow{2}{*}{$\frac{\text { QTH L1 }}{0.97^{\mathrm{f}}}$} & \multirow{2}{*}{$\begin{array}{r}\text { LED L2 } \\
0.84^{\mathrm{f}} \\
\end{array}$} \\
\hline & & & & & \\
\hline \multirow{4}{*}{$\begin{array}{c}\text { Lava } \\
\text { Ultimate } \\
\text { C1 }\end{array}$} & $\mathrm{T} 1=0.5 \mathrm{~mm}$ & $2.292^{\mathrm{c}}$ & $2.10^{\mathrm{d}}$ & $1.092^{\mathrm{f}}$ & $1.088^{\mathrm{f}}$ \\
\hline & $\mathrm{T} 2=0.7 \mathrm{~mm}$ & $2.330^{\mathrm{bc}}$ & $2.13^{\mathrm{d}}$ & $1.134^{\mathrm{ef}}$ & $1.180^{\mathrm{ef}}$ \\
\hline & $\mathrm{T} 3=0.9 \mathrm{~mm}$ & $2.770^{\mathrm{ab}}$ & $2.55^{\mathrm{ab}}$ & $1.224^{\mathrm{e}}$ & $1.208^{\mathrm{e}}$ \\
\hline & $\mathrm{T} 4=-1.2 \mathrm{~mm}$ & $2.912^{\mathrm{a}}$ & $2.88^{\mathrm{a}}$ & $1.422^{\mathrm{e}}$ & $1.460^{\mathrm{e}}$ \\
\hline \multirow{4}{*}{$\begin{array}{c}\text { Vita } \\
\text { Enamic } \\
\text { C2 }\end{array}$} & $\mathrm{T} 1=0.5 \mathrm{~mm}$ & $2.310^{\mathrm{c}}$ & $1.97^{\mathrm{de}}$ & $1.012^{\mathrm{f}}$ & $0.870^{\mathrm{f}}$ \\
\hline & $\mathrm{T} 2=0.7 \mathrm{~mm}$ & $2.392^{\mathrm{bc}}$ & $2.01^{\mathrm{d}}$ & $1.090^{\mathrm{f}}$ & $0.960^{f}$ \\
\hline & $\mathrm{T} 3=0.9 \mathrm{~mm}$ & $2.800^{\mathrm{a}}$ & $2.21^{\mathrm{d}}$ & $1.208^{\mathrm{e}}$ & $1.056^{\mathrm{f}}$ \\
\hline & $\mathrm{T} 4=1.2 \mathrm{~mm}$ & $2.942^{\mathrm{a}}$ & $2.15^{\mathrm{d}}$ & $1.424^{\mathrm{e}}$ & $1.208^{\mathrm{e}}$ \\
\hline
\end{tabular}

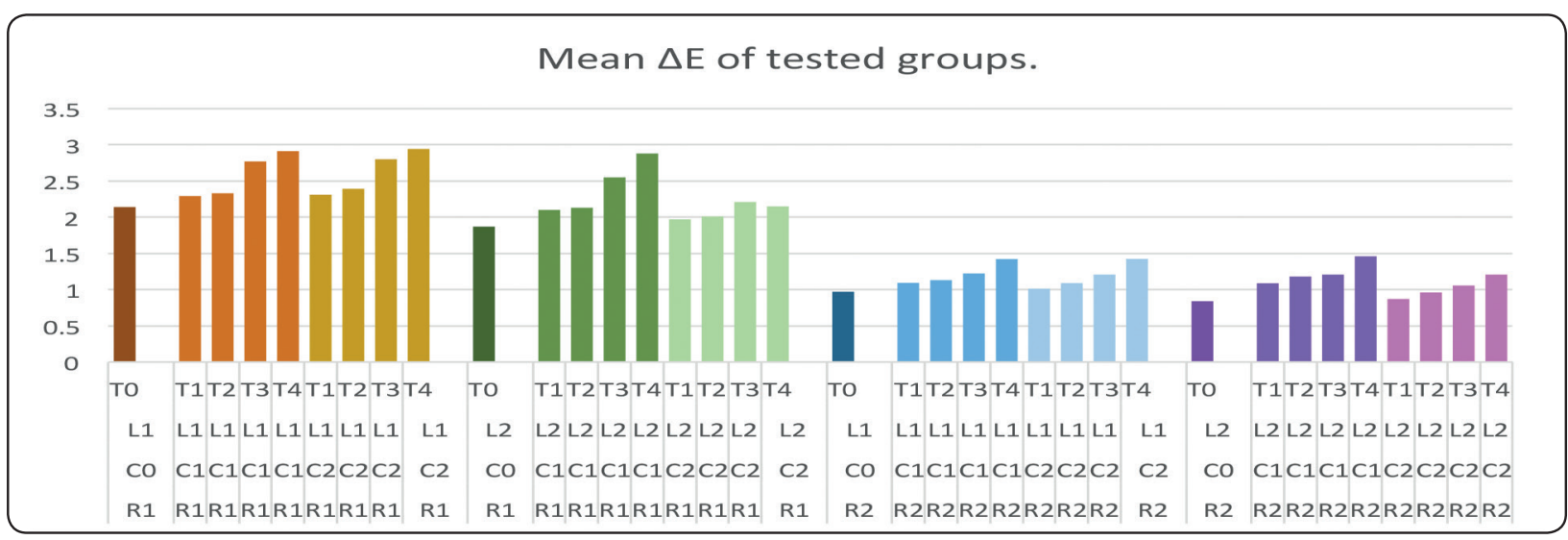

Fig. (2) Bar chart of Mean $\Delta \mathrm{E}$ of tested groups 
with LED L2 although there was an increase, this increase was not statistically significant.

Nexus 3 LC R2 groups showed no statistical significant difference in between each tested group compared to their control except, for the thickness $1.2 \mathrm{~mm}$ of Lava Ultimate $\mathrm{C} 1$ a statistical significant difference was obtained.

\section{Micro Hardness:}

The VHN mean values and standard deviations of tested groups are presented in (Table 7) and Fig 3. No significant interaction was detected between the four tested main effects. No significant difference was detected between the control groups and their corresponding $0.5 \mathrm{~mm} \mathrm{~T} 1$ thicknesses

Nexus 3 light R2 was less affected than Vario Link daul R1 by either the type or the thicknesses of the CAD/CAM material used in the current study. Also Nexus 3 light R2 showed lower VHN than Vario Link daul R1 which had a significantly higher VHN at thicknesses $0.7 \mathrm{~mm} \mathrm{T2}$ and $0.5 \mathrm{~mm}$ $\mathrm{T} 1$. Most of the groups showed a drop in the VHN at $1.2 \mathrm{~mm} \mathrm{~T} 4$

The thickness of the CAD/CAM material and the type of the resin luting cement had a significant effect on VHN than did either the type of CAD/ CAM material or the curing unit.

TABLE (7) Mean VHN of tested groups.

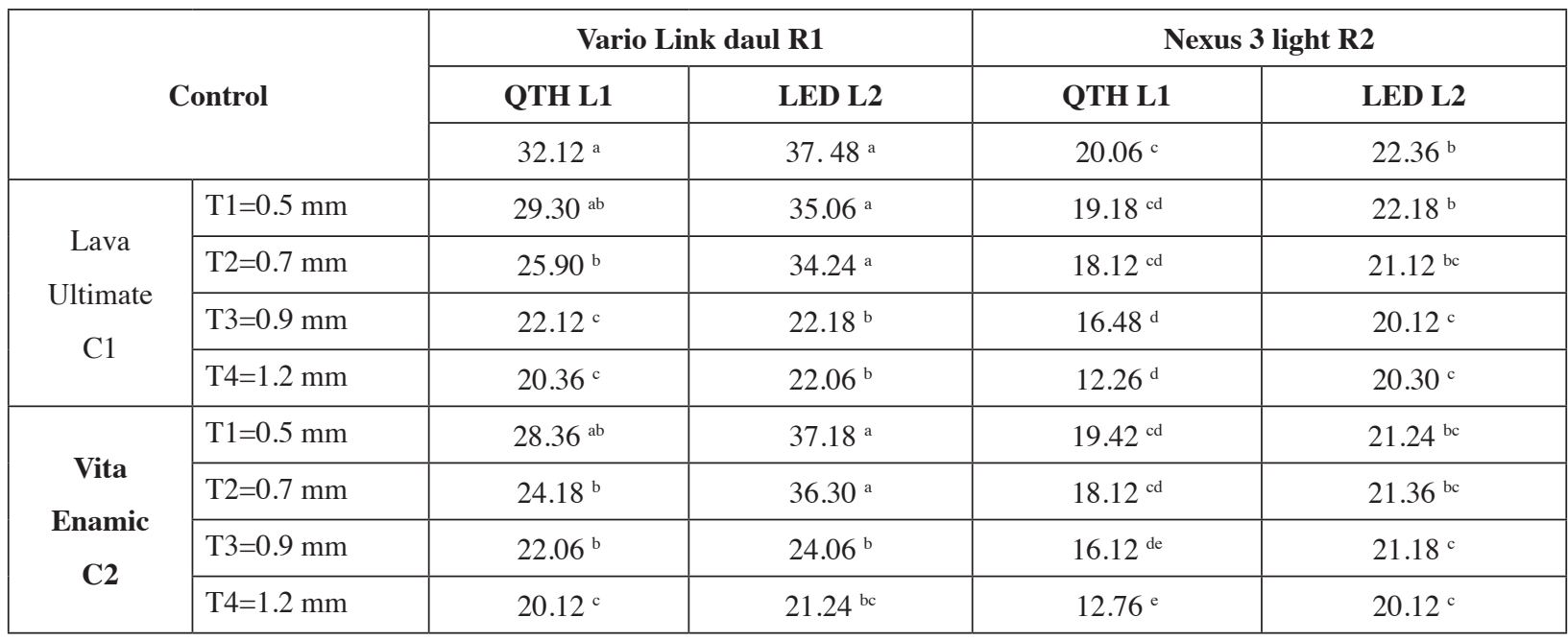

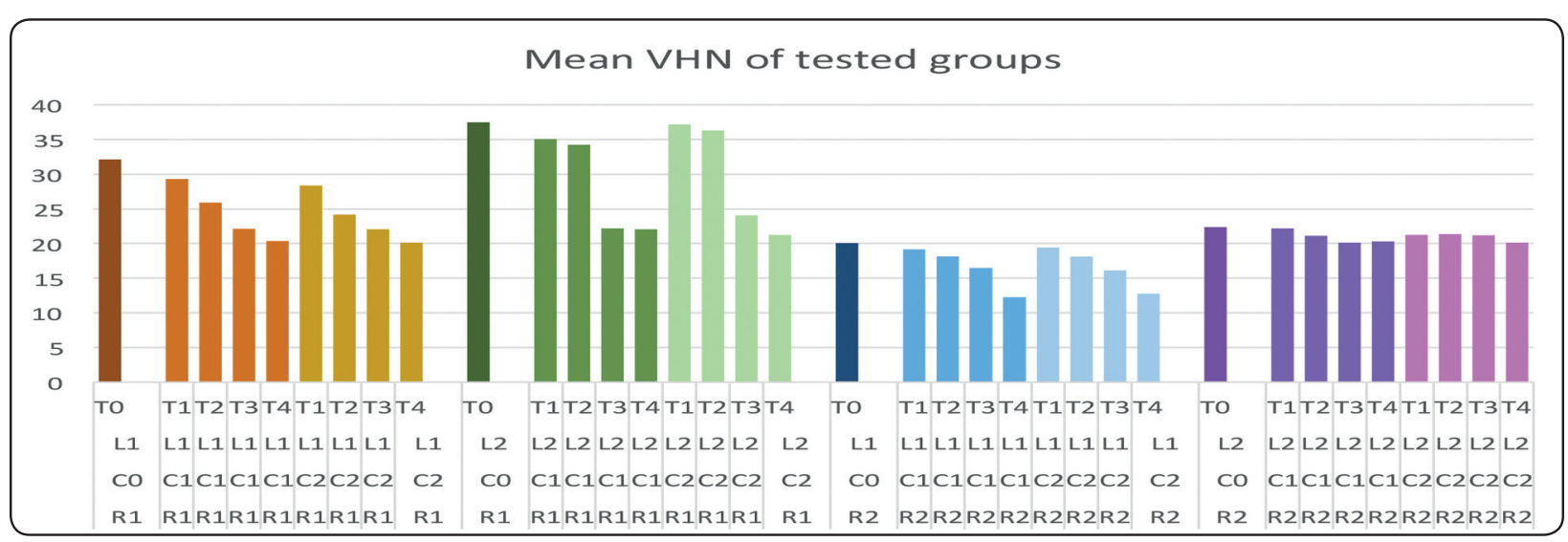

Fig (3) Bar chart of Mean $\Delta \mathrm{E}$ of tested groups 


\section{DISCUSSION}

The final shade of the resin luting cement is highly influenced by the degree of conversion which in turn can be evaluated indirectly by surface hardness measurements whether using Vickers or knop indenter which will give good determination after 24 hours ${ }^{(16)}$. Off course, the maturation of resin composite will continue in slow rate, sometimes a week ${ }^{(17,18)}$, and that is why in the current study the measurements were taken after one week.

Different CAD/CAM material thicknesses selected in this study represent the average preparation depths recommended by the manufacturer in different situations ${ }^{(1,2,19)}$.

Dual curing was introduced to insure full polymerization of resin composite luting cements in areas where light cannot reach with an efficient intensity. Yet, it was mentioned in literature that auto cure alone was incapable by itself to deliver full maturation of the resin composite cement in absence of photo initiated polymerization ${ }^{(20)}$.

Color differences can be evaluated visually or by color measurement devices. Most color measurement devices utilized in dentistry use the $\Delta E$ from the Commission International d'Eclairage CIE $\left(L^{*} a^{*} b^{*}\right)$ color system to determine color differences or changes. In this scheme, color is measured in three coordinate dimensions of $L^{*}$, which represents lightness (from white to black; similar to value), $a^{*}$, which corresponds to the greenred axis (negative value indicates green; positive value indicates red), and $b^{*}$, which corresponds to the blue-yellow axis (negative value indicates blue; positive value indicates yellow).

Although the used CAD/CAM materials acts as a light barrier during photo initiation of resin luting cements, yet their translucency may play a major role, allowing sufficient delivery of curing wave length to the under lying maturing material. Therefore, a greater degree of conversion leading to harder resin with a more stable color after polymerization $^{(21,22,23,24)}$.

The intensity of the photo initiation unit may have played an important role, as the marked difference in the intensity between both QTH and LED light curing units used may have contributed in the results of the study.

Visible light's wavelength fall in the range between 4/10 to 7/10 micrometer, and CAD/CAM materials and resin cements used, can contain a wide range of filler particles sizes that are larger or smaller than this wavelength ${ }^{(25)}$. Upon falling of light on the surface of filler particle larger than the wavelength of light, light diffuse occur as a result of its refraction and reflection infinitely on the surfaces of those particles. A similar phenomenon occurs as a result of the porosity of CAD/CAM materials ${ }^{(26,27)}$. The greater the refractive index difference between particle size and matrix of either materials, the greater the refraction and reflection of light, which leads to an opaque effect in CAD/CAM materials ${ }^{(28)}$, and that is why the more translucent material (Vita Enamic) didn't affect the intensity of the curing light as did the less translucent ${ }^{(29)}$ (Lava Ultimate).

Dual cured resin luting cements have a two different amines, one to react with benzoyl peroxide and another to react with camphorquinone. The amine that react with benzoyl peroxide is usually aromatic and more prone to degradation, whereas the coinitiator in the light polymerization system is usually aliphatic and more chemically stable, tending to cause less color variation ${ }^{(30)}$. The color instability of Dual cured resin luting cements is attributed to the presence of unreacted benzoyl peroxide. The reaction between benzoyl peroxide and amine is not very efficient, as it depends on the physical encounter of these molecules for chemical interaction during polymerization. The mobility of the initiators becomes restricted as the cement matures and become more viscous, leaving unreacted radical in the polymer chain. ${ }^{(31)}$ 
The quality of maturation of a resin luting cement is dependent on the use of a compatible light curing unit and with a proper light exposure time and intensity ${ }^{(32)}$ that is dictated by the thickness as well as the reactivity of the photo-initiator. It was found that hardness of a resin luting cement decreases as the thickness of CAD/CAM material increases ${ }^{(19,33,34)}$.

In our study by increasing the distance between the surface of the maturing resin composite luting cement and the photo initiation source, due to increasing the thickness of the CAD/CAM material led to a drop in microhardness.

Dual cure resin luting cement was capable of producing higher VHN though out the study which may be attributed to progress in polymerization and maturation of the cement after the light initiation time has stopped and till the activity of free radicles is controlled by the growing highly cross-linked polymeric network ${ }^{(35)}$.

The extent of resin cement maturation changes considerably among products under various curing conditions ${ }^{(36)}$. Clinicians should optimize the materials choice taking into account the curing characteristics of the cements.

Upon comparing the effect of different thicknesses of the two tested CAD/CAM materials, type of resin luting cement, and type of photo initiating devices on the hardness of the resin luting cement. A drop in VHN was noticed with increasing the CAD/CAM thickness, this drop is consistent with other studies ${ }^{(8,37)}$ and also in agreement with Koch et al. who stated that the ease at which light flows though ceramics is proportional with their thickness. ${ }^{(38)}$ The thickness of CAD/CAM material was considered as the primary factor determining the light transmittance available for polymerization $^{(20,39)}$.

Results of the current study uncovered that increasing the opacity as well as the distance between the light source and the maturing resin luting cement have a negative effect on its $\Delta \mathrm{E}$ and $\mathrm{VHN}$, and this was in agreement with literature ${ }^{(37-40)}$.

\section{CONCLUSION}

Within the limitation of this study, it could be concluded that, the thickness of the CAD/CAM material and the type of the resin luting cement had a higher effect on the $\Delta \mathrm{E}$ and VHN hence the degree of maturation of resin luting cement than did either the type of tested CAD/CAM materials or the curing units.

\section{REFERANCES}

1. Lava Ultimate "Restorative Instruction for USA". 3M ESPE 2015

2. VITA ENAMIC "Technical and scientific documentation". VITA Zahnfabrik 2015

3. He LH, Swain M. A novel polymer infiltrated ceramic dental material. Dent Mater 2011;27:527-34.

4. Swain MV, Coldea A, Bilkhair A, Guess PC. Interpenetrating network ceramic-resin composite dental restorative materials. Dent Mater 2015; 32:34-42.

5. Awada A, Nathanson D. Mechanical properties of resinceramic CAD/CAM restorative materials. J Prosthet Dent 2015; 114: 587-593.

6. Shembish FA, Tong H, Kaizer M, Janal MN, Thompson VP, Opdam NJ, Zhang Y. Fatigue resistance of CAD/CAM resin composite molar crowns. Dent Mater 2016; 32: 499-509.

7. Stawarczk B, Liebermann A, Eichberger M, Güth JF. Evaluation of mechanical and optical behavior of current esthetic dental restorative CAD/CAM composites. J Mech Behave Biomed Mater 2015; 55: 1-11.

8. Meng X, Yoshida K, Atsuts M, Hardness development of dual-cured resin cements through different thicknesses of ceramics. Dent mater J 2006 mar;25(1):132-137.

9. Blackman RB. Ceramic shade prescriptions for work authorizations. J Prosthet Dent 1982; 47: 28-35.

10. Barghi N, McAlister EH. LED and halogen lights: effect of ceramic thickness and shade on curing luting resin. Compend Contin Educ Dent 2003; 24: 497-500. 
11. Brewer JD, Akers CK, Garlapo DA, Sorensen SE. Spectrometric analysis of the influence of metal substrates on the color of metal-ceramic restorations. J Dent Res 1985; 64: 74-77.

12. Johnston WM. Color measurement in dentistry. J Dent 2009; 37 Suppl 1: e2-6.

13. Seghi RR, Hewlett ER, Kim J. Visual and instrumental colorimetric assessments of small color differences on translucent dental porcelain. J Dent Res 1989; 68: 1760-1764.

14. Seghi RR, Gritz MD, Kim J. Colorimetric changes in composites resulting from visible-light-initiated polymerization. Dent Mater 1990; 6: 133-137.

15. Canay S, Cehreli MC. The effect of current bleaching agents on the color of light-polymerized composites in vitro. J Prosthet Dent 2003; 89: 474-478.

16. Czasch P, Ilie N. In vitro comparison of mechanical properties and degree of cure of bulk fill composites. Clin Oral Investing 2013:227-35.

17. Musanje L, Darvell BW. Polymerization of resin composite restorative materials: exposure reciprocity. Dental Materials 2003; 19:531-41.

18. Musanje L, Darvell BW. Polymerization of resin composite restorative materials: exposure reciprocity. Dental Materials $2003 ; 19: 531-41$.

19. Karaagaclioglu L, Yilmaz B. Influence of cement shade and water storage on the final color of leucite-reinforced ceramics. Oper Dent 2008; 33: 386-391.

20. Alqahtani MQ, Aljurais RM and Alshaafi MM. The effects of different shades of resin luting cement on the color of ceramic veneers. Dental Materials Journal 2012; 31(3): 354-361

21. Mendes LC, Matos IC, Miranda MS, Benzi MR. DualCuring, Self-Adhesive Resin Cement: Influence of the Polymerization Modes on the Degree of Conversion and Microhardness Materials Research. 2010; 13(2): 171-176

22. Chen XD, Guang Hong G, Xing WZ, Wang YN. The influence of resin cements on the final color of ceramic veneers journal of prosthodontic research 59 (2015) 172-177

23. Heffernan MJ, Aquilino SA, Diaz-Arnold AM, Haselton DR, Stanford CM, Vargas MA. Relative translucency of six all-ceramic systems. Part II: core and veneer materials. J Prosthet Dent 2002; 88: 10-15.
24. Shimada K, Nakazawa M, Kakehashi Y, Matsumura H. Influence of abutment materials on the resultant color of heat-pressed lithium disilicate ceramics. Dent Mater J 2006; 25: 20-25.

25. Alqahtani MQ, Rana M, Aljurais RM, Alshaafi MM. The effects of different shades of resin luting cement on the color of ceramic veneers. Dent Mater J 2012; 31(3): 354-361

26. Almeida JR, DDS, Schmitt GU, Kaizer MR, Boscato N, Moraes RR. Resin-based luting agents and color stability of bonded ceramic veneers Journal of prosthetic dentistry 2015, Volume 114, Issue 2, 272-277

27. SulaimanTA, Abdulmajeed AA, Donovan TE, Ritter AV, Lassila LV, Vallittu PK, Närhi TO. Degree of conversion of dual-polymerizing cements light polymerized through monolithic zirconia of different thicknesses and types. Journal of prosthetic dentistry 2015, Volume 114, Issue 1, 103-108

28. Research and Development Ivoclar Vivadent AG, 9494 Schaan / Liechtenstein REPORT No. 22 July 2016

29. Faria-e-Silva AL, Pfeifer CS. Effectiveness of high-power LEDs to polymerize resin cements through ceramics: An in vitro study. Journal of prosthetic dentistry 2017, Volume 118, Issue 5, 631-636

30. Scotti N, Comba A, Cadenaro M, Fontanive L, Breschi L, Monaco C, Scotti R. Effect of lithium di-silicate veneers of different thickness on the degree of conversion and microhardness of a light-curing and a dual-curing cement. Int $\mathrm{J}$ Prosthodont 2016;29:384-8.

31. Shadman N, Atai M, Ghavam M, Kermanshah H, Ebrahimi SF. Parameters Affecting Degree of Conversion of DualCure Resin Cements in the Root Canal: FTIR Analysis. J Can Dent Assoc 2012; 78:c53

32. Pereira SG, Fulgêncio R, Nunes TG, Toledano M, Osorio $\mathrm{R}$, Carvalhode RM. Effect of curing protocol on the polymerization of dual-cured resin cements. Volume 26, Issue 7, July 2010, Pages 710-718

33. Meng X, Yoshida K, Atsuts M. influence of ceramic thickness on the mechanical properties and polymer structure of dual-cured resin luting agents Dent mater J 2008 may;24(5):594-599.

34. Koch A, Kroeger M, Hartung M, Manetsberger I, Hiller KA, Schmalz G, Friedl KH. Influence of ceramic translucency on curing efficacy of different light-curing units. J Adhes Dent 2007; 9:449-62. 
35. Lee JW, Cha HS, Lee JH. Curing efficiency of various resin-based materials polymerized through different ceramic thicknesses and curing time. J Adv Prosthodont. 2011 Sep;3(3):126-131.

36. El-Mowafy O, Rudo M, Influence of composite inlay/ onlay thickness on hardening of dual-cured resin luting agents. J CanDEntAssoc 2000 Mar; 66(3):147.

37. BinMahfooz AM, Qutub OA, Marghalani TY, Ayad MF, Maghrabi AA. Degree of conversion of resin cement with varying methacrylate compositions used to cement fiber dowels: A Raman spectroscopy study. The Journal of Pros- thetic Dentistry, In press, corrected proof, Available online 15 November 2017

38. Atai M, Watts DC, Atai Z. Shrinkage strain-rates of dental resin-monomer and composite systems. Bio-materials. $2005 ; 26(24): 5015-20$.

39. Dirxen C, Blunck U, Preissner S. Clinical performance of a new biomimetic double network material. Open Dent J 2013;7:118-22.

40. Alvaro DB, Corazza PH, Yu Z. Characterization of a polymer-infiltrated ceramic-network material. Dent Mater 2014;30:564-9. 